\title{
A workforce survey of Australian chiropractic: the profile and practice features of a nationally representative sample of 2,005 chiropractors
}

\author{
Jon Adams ${ }^{1 *}$, Romy Lauche ${ }^{1} \mathbb{D}$, Wenbo Peng ${ }^{1}$, Amie Steel ${ }^{1,2}$, Craig Moore ${ }^{1}$, Lyndon G. Amorin-Woods ${ }^{3}$
} and David Sibbritt ${ }^{1}$

\begin{abstract}
Background: This paper reports the profile of the Australian chiropractic workforce and characteristics of chiropractic care from a large nationally-representative sample of practitioners.

Methods: A 21-item questionnaire examining practitioner, practice and clinical management characteristics was distributed to all registered chiropractors $(n=4,684)$ in Australia in 2015 via both online and hard copy mail out.

Results: The survey attracted a response rate of $43 \%(n=2,005)$, and the sample is largely representative of the national chiropractic workforce on a number of key indicators. The average age of the chiropractors was 42.1 years, nearly two-thirds are male, and the vast majority hold a bachelor degree or higher qualification. Australian chiropractors are focused upon treating people across a wide age range who mainly present with musculoskeletal conditions. Australian chiropractors have referral relationships with a range of conventional, allied health and complementary medicine (CAM) providers.
\end{abstract}

Conclusion: The chiropractic profession represents a substantial component of the contemporary Australian health care system with chiropractors managing an estimated 21.3 million patient visits per year. While the Australian chiropractic workforce is well educated, research engagement and research capacity remains sub-optimal and there is much room for further capacity building to help chiropractic reach full potential as a key integrated profession within an evidence-based health care system. Further rich, in-depth research is warranted to improve our understanding of the role of chiropractic within the Australian health care system.

Keywords: Chiropractic, Chiropractor, Complementary and alternative medicine, Workforce, Practice-based research network

\section{Background}

Chiropractic constitutes a substantial component of health care seeking in Australia and worldwide [1, 2], with a 12month utilisation prevalence of $16 \%$ in Australia [2]. In 2014, the chiropractic profession had a registered workforce of 4,684 practitioners in Australia [3] represented by two major organisations - the Chiropractors' Association

\footnotetext{
* Correspondence: jon.adams@uts.edu.au

${ }^{1}$ Australian Research Centre in Complementary and Integrative Medicine (ARCCIM), University of Technology Sydney, Level 8, Building 10, 235-253 Jones Street, Ultimo, NSW 2007, Australia

Full list of author information is available at the end of the article
}

of Australia (CAA) and the Chiropractic and Osteopathic College of Australasia (COCA). Annual expenditure on chiropractic care (alone or combined with osteopathy) in Australia is estimated to be between AUD\$750-988 million $[2,4,5]$ with musculoskeletal complaints such as back and neck pain making up the bulk of consultations [2, 6-8]; and proportional expenditure is similar to that found in other countries [9-13]. While Medicare (the Australian publicly funded universal health care scheme) coverage of chiropractic services is limited to only those directed by a medical referral to assist chronic disease management [14], most private health insurers in Australia do provide 
partial reimbursement for a wider range of chiropractic services [15] in addition to limited third party payments for workers compensation and motor vehicle accidents.

As for the Australian workforce characteristics of the chiropractic profession, previous surveys show that the majority of chiropractors are male (64-67\%) and aged between 25 and 54 years (80.3\%); with $16 \%$ of practitioners aged 55 years or older $[3,16]$. In addition, the majority (>90\%) of chiropractors in Australia are university educated and hold a bachelor or postgraduate degree [1]. The vast majority of Australian chiropractors work full-time dedicating 33 working hours per week on average [16]. While previous Australian surveys have provided important insights into basic chiropractic workforce characteristics, they have often lacked rich, in-depth examination of core aspects of practice and clinical management characteristics $[1,16]$; and/or have drawn upon small local samples raising doubts around the generalisability of their results [17].

Yet, in-depth, national Australian chiropractic workforce data is vital for helping understanding the existing workforce, supporting future workforce planning, and helping determine if chiropractic training, education and research adequately reflect the practice characteristics and techniques/methods used in grass-roots daily routine care. Moreover, such workforce data also helps appreciate the current and potential interface of chiropractors with other health providers and the role of chiropractors within the wider Australian health system.

In direct response to this significant research gap, this paper provides an in-depth examination of the profile of the Australian chiropractic workforce and characteristics of chiropractic care from a large nationally-representative sample of practitioners.

\section{Methods}

This paper reports analyses from a questionnaire distributed as part of the recruitment for the Australian Chiropractic Research Network (ACORN) project - a national practice-based research network (PBRN) independently designed and conducted by senior researchers at the Australian Research Centre in Complementary and Integrative Medicine (ARCCIM), Faculty of Health, University of Technology Sydney. As part of the recruitment for the ACORN PBRN a 21-item practitioner questionnaire was distributed to all registered chiropractors across Australia [18]. While completion of the practitioner questionnaire was a prerequisite for inclusion in the ACORN PBRN database (Of the 2,005 participants reported in this paper 1,680 chiropractors also consented to be included in the ACORN PBRN practitioner database, i.e. $83.8 \%$ of responders) [19] it was also possible for chiropractors to complete the practitioner questionnaire but not consent to participate in the ongoing PBRN. The analyses reported in this paper focuses specifically upon the data gathered from the practitioner questionnaires regardless of the responder providing or not providing consent to be included in the ACORN PBRN database.

\section{Recruitment and sample}

Recruitment for the ACORN PBRN including the practitioner questionnaire reported in this paper was conducted between March and June 2015 and consisted of an invitation pack distributed to all registered chiropractors via both professional organisations and a professionwide mail out based on publically available information (including non-members). The invitation pack was also distributed via a number of regional chiropractic-related conferences and events and was also made available online through the ACORN website during the recruitment period. All participants were offered opportunity to complete the practitioner questionnaire via either online access (SurveyGizmo ${ }^{\mathrm{Tu}}$ ) or hard copy. A reminder invitation pack was distributed four weeks following initial invitation pack distribution via the same channels and 4 reminders were sent to potential participants via email where possible. Further details regarding the ACORN PBRN recruitment and promotion strategies can be found elsewhere [19].

At the time of recruitment there were 4,684 registered chiropractors in Australia and 2,005 chiropractors completed the questionnaire providing a response rate of $43 \%$. Of those 1,119 (55.8\%) returned a hard copy questionnaire and 886 chiropractors (44.2\%) participated in the online survey. In total, $92.8 \%$ of respondents were members of one or both of the two major organisations (CAA and COCA) and $2.7 \%$ of respondents were not members of either organisation. Compared to the entirety of registered chiropractors as registered by AHPRA in March 2015 [3] the sample of questionnaire respondents has been found to be representative in terms of gender $(p=0.634)$ and age $(p=0.065)$. While the workforce sample is also generally representative of the wider chiropractic population regarding practice location, we found slight differences in terms of the distribution of State of residency with the workforce sample slightly over-represented by chiropractors from South Australia, the Australian Capital Territory, Tasmania and the Northern Territory $(p<0.01)$ [19].

\section{Questionnaire}

The instrument used for this study consisted of a 21item questionnaire including examination of practitioner characteristics, practice characteristics, and clinical management. The questionnaire was developed by an interdisciplinary ACORN Project Steering Committee and subsequently pilot tested amongst a sample of chiropractors to ensure the final format, content and wording 
were practitioner-sensitive, readily understood and as timely to complete as reasonably possible.

The chiropractic practitioner characteristics examined included age, gender, number of years in private chiropractic practice, highest level of chiropractic professional qualification attained, professional organisation membership, and roles as a chiropractor in the previous 12 months. The practice characteristics included average patient care hours and patient visits per week, number of practice locations, area of practice location (urban, rural, remote), State/Territory of practice, other health professionals working in their practice location, professional referral relationships (sending and/or receiving referrals), use of diagnostic imaging, and use of electronic records. Clinical management measures included the frequency of discussion with patients regarding lifestyle aspects of care/ management plans, frequency with which chiropractors treat people across a range of conditions and broader patient subgroups, and the frequency with which chiropractors employ a range of techniques/methods and musculoskeletal interventions within their patient management.

\section{Statistical analyses}

All data were imported into the statistical software Stata 13.1. Data were checked for plausibility and cleaned for outliers. Data are presented in absolute and relative frequencies for dichotomous or categorical variables, as well as means and standard deviations for continuous variables.

\section{Results}

\section{Practitioner characteristics}

Of the 2,005 chiropractors who participated, $62.4 \%$ were male and the average age was $42.1(\mathrm{SD}=12.1$ ) years. Nearly all chiropractors (97.1\%) had a bachelor degree or higher, with the majority of chiropractor's highest professional qualification being a bachelor or double bachelor degree (34.6\%), followed by a Master's degree (32.7\%), Doctor of Chiropractic (28.9\%) or $\mathrm{PhD}(0.9 \%)$. Only a small number of chiropractor's highest professional qualification was a diploma $(2.1 \%)$ or advanced diploma $(0.8 \%)$. The average number of years in practice was $15.8(\mathrm{SD}=11.3)$ years.

Other than private practice, the respondents report being involved in a number of other roles as a chiropractor in the previous 12 months, including: university teaching $(7.2 \%)$, research $(6.0 \%)$, clinical supervision (10.5\%), volunteer work $(18.3 \%)$, and professional organisation activities (19.4\%).

\section{Practice characteristics}

The majority of chiropractors are based in (the State of) New South Wales (34.4\%), followed by Victoria (24.3\%), Queensland (14.5\%), Western Australia (13.3\%), South
Australia (8.9\%), Australian Capital Territory (2.3\%), Tasmania (1.5\%), and the Northern Territory (0.8\%). Overall $7.3 \%$ of chiropractors routinely consulted patients in a language other than English, with $61.4 \%$ of those chiropractors consulting in European languages, and $36.6 \%$ in Asian languages (Multiple languages possible). It should also be mentioned that $1.4 \%$ of those chiropractors consulted in some sign languages.

Most chiropractors are located in an urban area (73.6\%); with $75.1 \%$ of chiropractors routinely consulting in one location only. Of those who practice in more than one location, $80.9 \%$ practice in two locations and $13.3 \%$ practice in 3 locations.

The majority of chiropractors $(78.1 \%)$ practice in a multipractitioner location, with $46.0 \%$ of all chiropractors working with one other health practitioner, and 19.2\% working with two other health practitioners (Table 1) with the most common 'other practitioner' type being another chiropractor $(56.6 \%)$, a massage therapist $(29.6 \%)$ or a psychologist/ counsellor $(12.0 \%)$. In terms of professional referral relationships, the chiropractors report sending and/or receiving referrals from GPs (55.1\%) followed by podiatrists (38.5\%), and physiotherapists (30.5\%), see Table 1.

The respondents report spending an average of 27.3 $(\mathrm{SD}=12.6)$ hours per week on patient care and providing an average of $87.3(\mathrm{SD}=57.7)$ patient visits per week. Diagnostic imaging is utilised as part of practice by $47.7 \%$ of the chiropractors on an 'often' basis, and $39.6 \%$ of the chiropractors on a 'sometimes' basis. One in five (20.2\%) of the chiropractors reported having imaging facilities or scanning tools available on site, including X-ray (14.9\%), MRI (3.2\%), surface electromyography (SEMG) (4.1\%), thermography (4.5\%), ultrasound (2.8\%), and other $(4.3 \%)$.

Table 1 Health care practitioners located in the same practice location and health practitioners in a professional referral relationship with chiropractors

\begin{tabular}{|c|c|c|}
\hline \multirow[t]{2}{*}{$\begin{array}{l}\text { Health Care } \\
\text { Practitioner }\end{array}$} & $\begin{array}{l}\text { Working in same } \\
\text { practice location }\end{array}$ & $\begin{array}{l}\text { Professional referral relationship } \\
\text { (sending and/or receiving) }\end{array}$ \\
\hline & $\%$ & $\%$ \\
\hline Chiropractor & 56.6 & - \\
\hline Massage therapist & 29.6 & 12.9 \\
\hline Naturopath & 10.8 & 6.1 \\
\hline Podiatrist & 9.1 & 38.5 \\
\hline Exercise physiologist & 6.3 & 15.1 \\
\hline Physiotherapist & 9.1 & 30.5 \\
\hline $\begin{array}{l}\text { Psychologist/ } \\
\text { counsellor }\end{array}$ & 12.0 & 13.8 \\
\hline GP & 6.2 & 55.1 \\
\hline Medical specialist & 2.7 & 15.5 \\
\hline Other(s) & 29.2 & 20.9 \\
\hline None & 21.9 & 23.4 \\
\hline
\end{tabular}


Electronic records are used by $41.7 \%$ of all respondents, with $33.0 \%$ of all the chiropractors using electronic records for initial history, $39.4 \%$ for subsequent patient visits, and $34.1 \%$ for examination findings.

\section{Clinical management}

The chiropractors report discussing a range of topics as part of their care/management plans (Table 2). The most

Table 2 Clinical management characteristics including components of the clinical care/management plan, subgroups of patients and conditions they present with at the chiropractors

\begin{tabular}{|c|c|}
\hline Clinical management & Percent often \\
\hline \multicolumn{2}{|l|}{ Discuss } \\
\hline Physical activity & 84.9 \\
\hline Diet/nutrition & 50.5 \\
\hline Occupational health and safety & 40.9 \\
\hline Nutritional supplements & 37.1 \\
\hline Smoking/drugs/alcohol & 24.8 \\
\hline Pain counselling & 24.6 \\
\hline Medications & 23.1 \\
\hline \multicolumn{2}{|l|}{ Patient subgroups } \\
\hline Older people (65 years and over) & 73.5 \\
\hline Athletes or sports people & 49.5 \\
\hline Children (4 to 18 years) & 53.2 \\
\hline Pregnant women & 36.7 \\
\hline People with work-related injuries & 36.2 \\
\hline Children (up to 3 years) & 30.1 \\
\hline People with traffic-related injuries & 13.7 \\
\hline Non-English speaking ethnic groups & 6.5 \\
\hline People receiving post-surgical rehabilitation & 6.4 \\
\hline Aboriginal and Torres Strait Islander people & 1.8 \\
\hline \multicolumn{2}{|l|}{ Presenting condition(s) } \\
\hline Low back pain (axial) & 94.7 \\
\hline Neck pain (axial) & 93.6 \\
\hline Headache disorders & 87.2 \\
\hline Thoracic pain (axial) & 84.7 \\
\hline Low back pain (referred/radicular) & 80.9 \\
\hline Spinal health maintenance/prevention & 73.1 \\
\hline Degenerative spine conditions & 64.8 \\
\hline Neck pain (referred/radicular) & 62.8 \\
\hline Upper limb musculoskeletal disorders & 62.6 \\
\hline Postural disorders & 61.3 \\
\hline Lower limb musculoskeletal disorders & 60.4 \\
\hline Migraine disorders & 53.0 \\
\hline Thoracic pain (referred/radicular) & 46.4 \\
\hline Non-musculoskeletal disorders & 30.0 \\
\hline
\end{tabular}

Numbers indicate percentage of chiropractors who discuss those topics/treat those patients on an often basis common topic discussed on an 'often' basis was physical activity (84.9\%), followed by diet/nutrition (50.5\%) and occupational health and safety (40.9\%). Chiropractors treat people presenting with a variety of conditions with low back pain (axial) (94.7\%), neck pain (axial) (93.6\%), and headache disorders (87.2\%) being the most common conditions treated on an 'often' basis (Table 2). In terms of subgroups of patients treated by chiropractors, $73.5 \%$ of chiropractors treat older people ( $\geq 65$ years) on an 'often' basis, $53.2 \%$ treat children ( $4-18$ years) on an 'often' basis, and $49.5 \%$ treat athletes or sports people on an 'often' basis (Table 2).

The chiropractors report employing a number of techniques and methods in their patient management (Table 3). The most common techniques/methods employed on an 'often' basis are: high velocity, low amplitude adjustment/ manipulation/mobilisation (82.2\%); extremity manipulation (58.8\%); drop-piece techniques/Thomson (53.7\%); and instrument adjusting (52.3\%). Chiropractors also use a range of musculoskeletal interventions in their patient management, with the most common intervention used on an 'often' basis being soft tissue therapy, trigger point therapy, massage therapy and/or stretching (66.1\%) followed by specific exercise therapy/rehabilitation/injury taping (49.3\%) and heat/cryotherapy (16.6\%) (Table 4).

Table 3 Clinical management characteristics including chiropractic techniques and methods, and musculoskeletal interventions used by chiropractors

\begin{tabular}{lc}
\hline Clinical management & Percent often \\
\hline Techniques/Methods & 82.2 \\
High velocity, low amplitude adjustment/ & 58.8 \\
manipulation/mobilisation & 53.7 \\
Extremity manipulation & 52.3 \\
Drop-piece techniques/Thomson ${ }^{\circledast}$ or similar & 44.0 \\
Instrumental adjusting & \\
Biomechanical pelvic blocking/sacro-occipital & 16.2 \\
technique & 13.3 \\
Applied Kinesiology (AK) & 8.0 \\
Functional neurology & 4.4 \\
Flexion-distraction & \\
Chiropractic BioPhysics & \\
Musculoskeletal intervention & 66.1 \\
Soft tissue therapy, trigger point therapy, massage & \\
therapy, stretching & \\
Specific exercise therapy/rehabilitation/injury taping & 49.3 \\
Heat/cryotherapy & 16.6 \\
Dry needling or acupuncture & 13.7 \\
Orthotics (foot care) & 10.1 \\
Electro-modalities (eg, TENS) & 9.8 \\
\hline
\end{tabular}

Numbers indicate percentage of chiropractors who discuss those topics/treat those patients on an often basis 
Table 4 Selected chiropractors' characteristics per practice in different states/territories. Numbers in percentage of chiropractors in each state/territory

\begin{tabular}{|c|c|c|c|c|c|c|c|c|}
\hline & $\begin{array}{l}\text { NSW } \\
n=680\end{array}$ & $\begin{array}{l}\text { VIC } \\
n=479\end{array}$ & $\begin{array}{l}\text { QLD } \\
n=479\end{array}$ & $\begin{array}{l}\text { WA } \\
n=263\end{array}$ & $\begin{array}{l}\text { SA } \\
n=175\end{array}$ & $\begin{array}{l}\text { TAS } \\
n=29\end{array}$ & $\begin{array}{l}\text { NT } \\
n=15\end{array}$ & $\begin{array}{l}\text { ACT } \\
n=46\end{array}$ \\
\hline \multicolumn{9}{|l|}{ Gender } \\
\hline Male & 65.1 & 59.2 & 62.5 & 59.0 & 65.1 & 69.0 & 86.7 & 52.2 \\
\hline Female & 34.9 & 40.8 & 37.5 & 41.0 & 34.9 & 31.0 & 13.3 & 47.8 \\
\hline \multicolumn{9}{|l|}{ Patient care } \\
\hline Hours, Mean \pm SD & $27.7 \pm 11.5$ & $26.5 \pm 10.9$ & $28.9 \pm 9.7$ & $24.1 \pm 10.6$ & $27.4 \pm 9.3$ & $25.5 \pm 13.0$ & $30.5 \pm 7.7$ & $24.7 \pm 8.6$ \\
\hline Visits, Mean \pm SD & $72.9 \pm 51.9$ & $86.6 \pm 57.3$ & $107.1 \pm 58.4$ & $94.1 \pm 64.1$ & $105.3 \pm 53.5$ & $97.2 \pm 70.5$ & $112.9 \pm 40.8$ & $73.3 \pm 42.0$ \\
\hline \multicolumn{9}{|l|}{ Area } \\
\hline Rural & 74.1 & 69.3 & 68.0 & 79.7 & 69.2 & 48.5 & 50.0 & 95.8 \\
\hline Rural & 7.9 & 12.4 & 13.7 & 7.5 & 14.1 & 24.2 & 21.4 & 4.2 \\
\hline Remote & 18.0 & 18.3 & 18.3 & 12.8 & 16.7 & 27.3 & 28.6 & 0.0 \\
\hline \multicolumn{9}{|l|}{ Qualification } \\
\hline Diploma & 3.1 & 1.7 & 2.5 & 0.0 & 4.1 & 3.6 & 0.0 & 0.0 \\
\hline Advanced Diploma & 0.7 & 0.8 & 0.7 & 0.8 & 0.6 & 0.0 & 0.0 & 2.2 \\
\hline Doctor of Chiropractic & 13.8 & 57.6 & 32.0 & 56.9 & 26.2 & 42.9 & 26.7 & 28.3 \\
\hline Bachelor & 38.4 & 17.8 & 33.5 & 20.0 & 32.0 & 32.1 & 46.7 & 32.6 \\
\hline Master's degree & 43.9 & 22.0 & 31.3 & 22.3 & 37.2 & 21.4 & 26.7 & 37.0 \\
\hline $\mathrm{PhD}$ & 1.0 & 0.8 & 0.7 & 0.4 & 0.6 & 0.0 & 0.0 & 0.0 \\
\hline Use of electronic records & 45.6 & 46.4 & 51.9 & 43.4 & 29.1 & 20.7 & 60.0 & 39.1 \\
\hline Use of imaging, often & 46.9 & 45.8 & 55.1 & 54.4 & 42.3 & 37.9 & 46.7 & 23.9 \\
\hline \multicolumn{9}{|l|}{ Referrals } \\
\hline GP & 58.7 & 55.1 & 57.1 & 55.1 & 54.9 & 72.4 & 60.0 & 50.0 \\
\hline Medical Specialist & 18.8 & 18.4 & 10.1 & 10.3 & 10.3 & 13.8 & 33.3 & 19.6 \\
\hline None & 20.3 & 24.0 & 22.0 & 20.2 & 16.6 & 24.1 & 26.7 & 17.4 \\
\hline Consulted in language other than English & 10.0 & 7.9 & 3.8 & 3.8 & 4.6 & 0.0 & 6.7 & 4.3 \\
\hline
\end{tabular}

\section{Discussion}

This is the first in-depth chiropractic workforce survey drawing upon a nationally representative sample of Australian chiropractors. This survey not only confirms basic findings from prior enquiries but also reveals a number of new and significant insights.

Our study findings add further weight to evidence that the national chiropractic workforce is becoming increasingly female over time. This trend was highlighted in a previous study [17], and seems to be further reflected in our more recent data. The chiropractic workforce is well educated with almost all practitioners having undertaken university training. This is not too surprising given that registration as a chiropractor in Australia requires completion of an accredited chiropractic program which is provided at public universities in Victoria, New South Wales, Western Australia and Queensland [20].

It is noticeable however that only $0.9 \%$ of chiropractors in our study currently have a $\mathrm{PhD}$. This level of $\mathrm{PhD}$ award represents only a small increase compared to the $0.7 \%$ identified in 2010 [17] and while comparable to other allied health care professions such as physiotherapy $[21,22]$ this finding does appear to indicate a somewhat limited capacity to conduct and lead research as well as supervise future chiropractic-focused $\mathrm{PhDs}$ within the current Australian chiropractic workforce [16]. The need for strengthening chiropractic research in Australia has been noted previously [23], and several steps have been proposed to generate and encourage chiropractic research capacity in Australia in the face of much needed improvement in research output and activity from within Australian chiropractic university departments [24]. Such a proposal is supported by findings that chiropractors do educate themselves using research literature [25], but often feel inadequately trained to conduct clinical research [26, 27]. Perhaps given the lack of PhDs amongst Australian chiropractors as identified in our study a beneficial approach for research capacity building may be to draw upon academics/methodologists beyond chiropractic to at least 
help lead or co-supervise PhD research [28] — in areas such public health, health services research and clinical research. Such research collaboration beyond the discipline of chiropractic would not only add much needed capacity but also ensure designs are rigorous and critical. The low number of $\mathrm{PhD}$ qualifications is countered by the large percentage of Master's degrees (>30\%) in the cohort, as such there is large potential within the chiropractic community to establish significant and sustainable research capacity.

In the context of research capacity building, it is interesting to note that $6 \%$ of the chiropractors in our study did report a personal engagement in research activities and while the specific type of research engagement is not known (it may possibly range from conducting or collaborating on a research activity to possibly having been a targeted participant in a research project) this finding does suggest there may at least be a relatively substantial level of research familiarity amongst chiropractors that the profession may be able to build upon for future research capacity building. Further research is required to explore the research-practitioner interface amongst chiropractors including examination of the perspectives and experiences amongst the ranks of the Australian chiropractic profession towards empirical enquiry and an evidence-based platform for practice.

Chiropractors in Australia also report an average of 27 patient contact hours per week across a wide patient age range. Previous reports have found chiropractors working an average of $33 \mathrm{~h}$ per week $[1,16]$, indicating that a substantive proportion of work may not include actual patient contact. Either way, results indicate significantly lower total working hours of chiropractors on average than those reported by other health professions, such as GPs who work around $45 \mathrm{~h}$ per week on average [29]. The low number of patient contact hours raises questions as to why chiropractors might be working so little, and more research is needed to determine if it is the chiropractors' choice, or if it is related to lack of patients, the level of intra- and interprofessional competition, or other unknown reasons which may have significant implications for the future workforce development. Chiropractors in our sample also report consulting an average of 87 patients per week, which equates to a chiropractor spending an average of around $20 \mathrm{~min}$ with each patient. An average consultation time that is more than double the reported average consultation time for a GP in Australia [30] but much less than the average consultation time (up to $60 \mathrm{~min}$ ) identified for other allied health and CAM practitioners [31, 32]. Based on the average patient visit data identified from our study we estimate that Australian chiropractors currently manage around 21.3 million patient visits per year and this figure would suggest chiropractors play a relatively substantial role in healthcare provision in contemporary Australia.
Another interesting finding from our analyses relates to the inter-professional relationship between chiropractors and other health care providers in Australia. While the vast majority of chiropractors in our study report working with another chiropractor or massage therapist in the same practice location, and only a minority of chiropractors report a GP or physiotherapist as working in their practice location, a large number of chiropractors are interconnected to GPs, physiotherapists and other health care professionals by sending and/or receiving referrals. Indeed, a substantial percentage of chiropractors in our study report having a referral relationship with GPs, physiotherapists and other health care professionals. This aligns with previous research that has found more than half of GPs regularly refer to chiropractors $[33,34]$ and that chiropractors understand and value the importance of referral relationships with other professions [35]. Some aspects of such referrals may also be related to health insurance, as chiropractic care is eligible for allied health services coverage (via Medicare, the Australian publicly funded universal health care scheme) if it is directed by a medical referral to assist chronic disease management [14]. However, recent findings indicate that only a minority of patients utilise chiropractic care via Medicare coverage [7]. Unfortunately, our study did not identify the direction of referrals between the chiropractors and GPs, and further research is warranted to explore both who initiatives referrals between GPs and chiropractors and the relative experiences of the two parties regarding these patient referrals with a view to helping facilitate more effective inter-professional collaboration. Further research is also required to examine the interplay between referral and the use of electronic records. The low number of chiropractors using electronic health records may negatively impact potential referral relationships, as well as future educational and training needs.

The vast majority of chiropractors report being consulted by patients with musculoskeletal conditions such as back and neck pain, which is in line with the traditional chiropractic focus on spinal health [36, 37]. It can also be assumed that the high percentage of thoracic spine conditions that patients present with is related to lifestyle factors and desktop workplace setups [38], and requires significant efforts in examining efficacy and safety of chiropractic treatments for those conditions. Accordingly, chiropractors use a broad range of manual techniques and musculoskeletal interventions suited for the treatment of back and neck pain. Of note is the finding from our study that chiropractic patient management includes a wide range of health advice on diet and nutrition, physical activity, minimising alcohol and smoking and drug consumption. These findings highlight the role and focus of chiropractors toward disease 
prevention and health promotion as reported in other studies [39-42] and there is a need to further assess the whether the chiropractic workforce may represent a valuable resource for promoting wider health promotion and prevention in Australia [43, 44].

Our findings may be limited due to several factors. The survey data was collected via self-report and this may have introduced a possible recall bias. Furthermore, the depth to which our questionnaire examined some workforce issues was further limited in view of encouraging a reasonable response rate and some of these issues will require follow-up in future research. Due to space limitations for example no detailed information on education and trainings, ethnicity, and attitudes and beliefs of chiropractors were explored; those issues will be examined in further sub studies. Nevertheless, despite these limitations, previous workforce surveys of Australian chiropractic have reported substantially lower response rates [17], and no previous research has attempted to attract a national representative sample of chiropractic care [17, 40]. The workforce survey reported here therefore comprises one of the largest scale voluntary workforce samples in the field of chiropractic or allied health care to date.

\section{Conclusion}

The chiropractic profession represents a substantial component of the contemporary Australian health care system. While the Australian chiropractic workforce is well educated, research engagement and capacity remains poor and there is much room for future initiatives to help chiropractic reach full potential as a key integrated profession within an evidence-based health care system. Further rich, in-depth research is required on a number of specific topics relating to the practice of chiropractors in Australia in order to ensure safe, effective and coordinated health care for all patients.

\section{Acknowledgement}

The ACORN project is funded by the Chiropractors' Association of Australia (CAA). We wish to thank the ACORN Steering Committee membership for their time and support and the CAA for their financial support for the ACORN PBRN. The ACORN PBRN is independently designed and conducted by members of the ARCCIM, UTS. The research reported in this paper is the sole responsibility of the authors and reflects the independent ideas and scholarship of the authors alone. We would also like to thank all participants for providing the data.

\section{Funding}

The ACORN project is funded by the Chiropractors' Association of Australia. The funding source had no influence in the design of the study and collection, analysis, and interpretation of data and in writing the manuscript. Craig Moore has received a PhD scholarship from the Chiropractors' Association of Australia however the scholarship does not fund work related to this paper.

\section{Availability of data and materials}

The datasets generated during and/or analysed during the current study are available from the corresponding author on reasonable request.

\section{Authors' contribution}

Designed the study: JA, DS; Collected the data: JA, DS, AS, CM, LAW; Analysed the data: DS. Interpreted the data: All authors; Wrote the first draft: $D S, R L, J A$; Critically revised the manuscript, and approved the final version: All authors.

\section{Competing interests}

The authors declare that they have no competing interest.

\section{Consent for publication}

Not applicable.

\section{Ethics approval and consent to participate}

The ACORN PBRN has been approved by the UTS Human Ethics Committee (approval \#2015000503). All participants provided written informed consent.

\section{Author details}

'Australian Research Centre in Complementary and Integrative Medicine (ARCCIM), University of Technology Sydney, Level 8, Building 10, 235-253 Jones Street, Ultimo, NSW 2007, Australia. ${ }^{2}$ Office of Research, Endeavour College of Natural Health, Brisbane, Australia. ${ }^{3}$ School of Health Professions, Murdoch University, Murdoch, Australia.

Received: 15 August 2016 Accepted: 14 December 2016

Published online: 05 January 2017

\section{References}

1. Leach MJ. Profile of the complementary and alternative medicine workforce across Australia, New Zealand, Canada, United States and United Kingdom. Complement Ther Med. 2013;21:364-78.

2. Xue CC, Zhang AL, Lin V, Myers R, Polus B, Story DF. Acupuncture, chiropractic and osteopathy use in Australia: a national population survey. BMC Public Health. 2008:8:105.

3. Chiropractic Board of Australia. Chiropractic registrant data: December 2014. Published 04 March 2015. Available at http://www.chiropracticboard.gov.au/ About-the-Board/Statistics.aspx. Last Assessed 3 May 2016. 2015.

4. Australian Bureau of Statistics. Chiropractic and Osteopathic Services. 8570.0 - Health Care Services 2009-2010. Available from http://www.abs.gov.au/ ausstats/abs@.nsf/Latestproducts/

095A883993D87E47CA2578C30014769F?opendocument. Last Accessed 15 Mar 2016. 2011.

5. Fitzpatrick N. IBIS World Industry Report Q8534: chiropractic and osteopathic services in Australia. [http://www.ibisworld.com.au/industry/ default.aspx?indid=620]. 2015.

6. Brown BT, Bonello R, Fernandez-Caamano R, Eaton S, Graham PL, Green H. Consumer characteristics and perceptions of chiropractic and chiropractic services in Australia: results from a cross-sectional survey. J Manipulative Physiol Ther. 2014;37:219-29.

7. French SD, Charity MJ, Forsdike K, Gunn JM, Polus BI, Walker BF, Chondros P, Britt HC. Chiropractic Observation and Analysis Study (COAST): providing an understanding of current chiropractic practice. Med J Aust. 2013;199:687-91.

8. Amorin-Woods LG, Parkin-Smith GF, Nedkoff L, Fisher C. Outcomes of a pilot study in chiropractic practices in Western Australia. Chiropr Man Therap. 2016;24:34.

9. Ailliet L, Rubinstein SM, de Vet HC. Characteristics of chiropractors and their patients in Belgium. J Manipulative Physiol Ther. 2010;33:618-25.

10. Coulter ID, Hurwitz EL, Adams AH, Genovese BJ, Hays R, Shekelle PG. Patients using chiropractors in North America: who are they, and why are they in chiropractic care? Spine (Phila Pa 1976). 2002;27:291-6. discussion 297-298.

11. Hartvigsen J, Sorensen LP, Graesborg K, Grunnet-Nilsson N. Chiropractic patients in Denmark: a short description of basic characteristics. J Manipulative Physiol Ther. 2002;25:162-7.

12. Leboeuf-Yde C, Hennius B, Rudberg E, Leufvenmark P, Thunman M. Chiropractic in Sweden: a short description of patients and treatment. J Manipulative Physiol Ther. 1997;20:507-10.

13. Rubinstein S, Pfeifle CE, van Tulder MW, Assendelft WJ. Chiropractic patients in the Netherlands: a descriptive study. J Manipulative Physiol Ther. 2000;23: 557-63.

14. Australian Government. Department of Health: Chronic Disease Management - Individual Allied Health Services under Medicare - Provider 
Information. 2014. Available at http://www.health.gov.au/internet/main/ publishing.nsf/content/22F660E959ABF390CA257BF0001F3CF3/\$File/Fact Sheet_CDM_Individual_Allied_Health_Services_Provider_Info_Feb_14.pdf. Accessed 15 Mar 2016.

15. Engel RM, Brown BT, Swain MS, Lystad RP. The provision of chiropractic, physiotherapy and osteopathic services within the Australian private healthcare system: a report of recent trends. Chiropr Man Therap. 2014;22:3.

16. AlHW National Health Workforce Data Set - Chiropractic workforce. Available at http://www.aihw.gov.au/workforce/chiropractic/. Last Accessed 25 Feb 2016.

17. Eaton S, Bonello R, Brown BT, Graham PL. Chiropractic practice in NSW: A description of demographic and practitioner characteristics. Chiro J Aus. 2012;42:114-21.

18. Adams J, Steel A, Chang S, Sibbritt D. Helping address the national research and research capacity needs of Australian chiropractic: introducing the Australian Chiropractic Research Network (ACORN) project. Chiropr Man Therap. 2015;23:12

19. Adams J, Steel A, Moore C, Amorin-Woods L, Sibbritt D. Establishing the ACORN national practitioner database: Strategies to recruit practitioners to a national Practice-Based Research Network. J Manip Physiol Ther. 2016;39: 594-602.

20. Brown BT, Bonello R, Fernandez-Caamano R, Graham PL, Eaton S, Green H. Chiropractic in Australia: survey of the general public. Chiro J Aus. 2013;43:85-92.

21. Anderson G, Ellis E, Williams V, Gates C. Profile of the physiotherapy profession in New South Wales (1975-2002). Aust J Physiother. 2005;51:109-16.

22. Mulcahy AJ, Jones S, Strauss G, Cooper I. The impact of recent physiotherapy graduates in the workforce: a study of Curtin University entry-level physiotherapists 2000-2004. Aust Health Rev. 2010;34:252-9.

23. Eaton S. The Australasian college of Chiropractors' research summit: investigating the significance of strategic research for the profession. Chiro J Aus. 2011:41:2

24. Swain M, Downie A, Brown BT, Lystad RP. A commentary to address the state of chiropractic research in Australia. Chiro J Aus. 2013:43:73-4.

25. Walker BF, Stomski NJ, Hebert JJ, French SD. Evidence-based practice in chiropractic practice: A survey of chiropractors' knowledge, skills, use of research literature and barriers to the use of research evidence. Complement Ther Med. 2014;22:286-95.

26. Alcantara J, Leach MJ. Chiropractic attitudes and utilization of evidence-based practice: the use of the EBASE questionnaire. Explore (NY). 2015:11:367-76.

27. Banzai R, Derby DC, Long CR, Hondras MA. International web survey of chiropractic students about evidence-based practice: a pilot study. Chiropr Man Therap. 2011;19:6.

28. Adams J, Sibbritt D, Broom A, Wardle J, Steel A, Murthy V, Daley J. Research capacity building in traditional, complementary and integrative medicine: Grass-roots action towards a broader vision. In: Adams J, Andrews GJ, Barnes J, Broom A, Magin P, editors. Traditional, Complementary and Integrative Medicine. UK: Palgrave Macmillan; 2012. p. 275-82.

29. Australian Institute of Health and Welfare. AIHW 2012. Medical workforce 2010. National health workforce series no. 1. Cat. no. HWL 47. Canberra: AlHW. Available at http://www.aihw.gov.au/publication-detail/?id= 10737421480. Last Assessed 31 Mar 2016. 2012.

30. Sayer GP, Britt H, Horn F, Bhasale A, McGeechan K, Charles J, Miller GC, Hull B, Scahill $S$. Measures of health and health care delivery in general practice in Australia: Supplementary Analysis of Nominated Data 1998-99. A joint report by the University of Sydney and the Australian Institute of Health and Welfare AlHW cat. no. GEP 3. Available at http://www.aihw.gov.au/WorkArea/ DownloadAsset.aspx?id=6442455926. Last assessed 31 Mar 2016. 2000 .

31. Casey M, Adams J, Sibbritt D. An examination of the clinical practices and perceptions of professional herbalists providing patient care concurrently with conventional medical practice in Australia. Complement Ther Med. 2008;16:228-32

32. Cherkin DC, Deyo RA, Sherman KJ, Hart LG, Street JH, Hrbek A, Davis RB, Cramer E, Milliman B, Booker J, et al. Characteristics of visits to licensed acupuncturists, chiropractors, massage therapists, and naturopathic physicians. J Am Board Fam Pract. 2002;15:463-72.

33. Cohen MM, Penman S, Pirotta M, Da Costa C. The integration of complementary therapies in Australian general practice: results of a national survey. J Altern Complement Med. 2005;11:995-1004.
34. Wardle JL, Sibbritt DW, Adams J. Referrals to chiropractors and osteopaths: a survey of general practitioners in rural and regional New South Wales, Australia. Chiropr Man Therap. 2013;21:5

35. Hsiao A, Ryan G, Hays R, Coulter ID, Andersen R, Wenger N. Variations in provider conceptions of integrative medicine. In: Adams J, Andrews GJ, Barnes J, Broom A, Magin P, editors. Traditional, complementary and integrative medicine. UK: Palgrave Macmillan; 2012. p. 159-67.

36. Bergmann TF, Peterson DH. Chiropractic technique principles and procedures, vol. 3. St. Louis, Missouri: Elsevier; 2010.

37. Chang M. The chiropractic scope of practice in the United States: a crosssectional survey. J Manipulative Physiol Ther. 2014;37:363-76.

38. Devereux JJ, Vlachonikolis IG, Buckle PW. Epidemiological study to investigate potential interaction between physical and psychosocial factors at work that may increase the risk of symptoms of musculoskeletal disorder of the neck and upper limb. Occup Environ Med. 2002:59:269-77.

39. McClelland G. The American Chiropractic Association and primary care. J Chiropr Med. 2002;1:180-3.

40. Rupert RL. A survey of practice patterns and the health promotion and prevention attitudes of US chiropractors. Maintenance care: part I. J Manipulative Physiol Ther. 2000;23:1-9.

41. Rupert RL, Manello D, Sandefur R. Maintenance care: health promotion services administered to US chiropractic patients aged 65 and older, part II. J Manipulative Physiol Ther. 2000;23:10-9.

42. Hawk C, Schneider M, Evans Jr MW, Redwood D. Consensus process to develop a best-practice document on the role of chiropractic care in health promotion, disease prevention, and wellness. J Manipulative Physiol Ther. 2012;35:556-67.

43. Wardle J, Adams J, Magalhaes RJ, Sibbritt D. Distribution of complementary and alternative medicine (CAM) providers in rural New South Wales, Australia: a step towards explaining high CAM use in rural health? Aust J Rural Health. 2011;19:197-204.

44. Amorin-Woods LG, Parkin-Smith GF, Nedkoff L, Fisher C. Critique of a practice-based pilot study in chiropractic practices in Western Australia. Chiropr Man Therap. 2016;24:38.

\section{Submit your next manuscript to BioMed Central and we will help you at every step:}

- We accept pre-submission inquiries

- Our selector tool helps you to find the most relevant journal

- We provide round the clock customer support

- Convenient online submission

- Thorough peer review

- Inclusion in PubMed and all major indexing services

- Maximum visibility for your research

Submit your manuscript at www.biomedcentral.com/submit 